\title{
嫌悪刺激の反復暴露に伴う不安反応の 時系列変化に関する研究
}

\section{Time series changes of anxiety response under repeated exposures to aversive stimulus}

\author{
IWANAGA, Makoto \\ Sakuyo College of Music \\ 1334-1, Yaide, Tsuyama-city, Okayama 708, Japan
}

The present study was designed to examine the relationship between inhibition and changes in the anxiety response during repeated exposures to noxious stimuli. Six repressers $(\mathrm{R})$ and 6 sensitizers ( $\mathrm{S}$ ), as defined by Byrne's RS scale, served as subjects. Experimental trials began with a 1 minute anticipatory period. An electrical shock of $10 \mathrm{~mA}$ as a noxious stimulus was presented for 0.1 second at the termination of the anticipatory period, which was continuously announced by the count down of figures. Experimental trials were repeated 10 times, with inter-trial intervals of about 5 minutes. Heart rate was used as an indicator of anxiety. Main findings were as follows : (1) The factor analysis for time series patterns of heart rate yielded three factors. (2) As trials were repeated, trend changed in heart rate decreased, while phasic changes increased. (3) Repressers showed inhibitory change in heart rate just before the noxious stimulus. The latter result indicated that a defense mechanism affected the expression of anxiety in repressers.

Key words : anxiety, repeated exposures, factor analysis, sensitizer, represser

【要 約】 本研究は, 嫌悪刺激の反復暴露にともなら不安反応の変化と抑制作用との関係につ いて検討することを目的とした。被験者はByrne の R S スケールを用いて分類し， sensitizer $(S)$ を 6 名, represser $(R)$ を 6 名用いた. 実験試行は，予期期間 1 分からなり，嫌悪 刺激である電撃を $10 \mathrm{~mA}$ の強さで, 1 秒間与兄た. 電撃の到来は, 数字のカウントダウンにより 継時的に予告した. 実験試行は数分間隔で10回反復した. 不安の測度として心拍数を用いた。得 られた結果は，以下の通りであった。（1）不安の時系列変化成分を因子分析により抽出した結 果，3因子が抽出できた。（2）反復数が増兄るにつれ，不安表出のトレンド的な変化成分が減少 し，細かな変動成分に移行することがわかった。 (3) 防衛機制の違いにより不安のみられ方が異 なり, represser では嫌悪刺激直前で不安の抑圧がみられた。 
予期性の不安を低減する 1 手段として, 嫌悪刺 激の反復呈示があげられる。Epstein \& Fenz (1965) は, 反復の効果を調べるため, パラシュー 卜降下前に見られる不安反応について, 初心者と 経験者の比較を行っている。初心者は, パラ シュート降下前夜よりも降下当日の不安が高く, 降下直前でピークに達するといら不安のパターン を示すことがわかった。それれ対して，経験者の 示す不安のピークはむしろ降下前夜以前にあり， 降下直前になると不安は低下することがわかっ た。しかし, 降下後に不安が増大寸る after discharge 現象が見られることから，不安が低減 していたのではなく，一時的に抑制されていたこ とがわかる。

Epstein (1971)は，実験室実験において，嫌悪刺 激の反復暴露の効果を検討している。空の結果, 心拍数の低下が見られた他に, 時系列変化パタ一 ンにも反復に伴ら違いが認められた。始めは, 嫌 悪刺激である電撃の到来に向けて心拍数が増加す る変化パターンを示していたが, セッションを重 ねるにつれ心拍数のピークは予期期間の中盤から 前半へと移行していき, 電撃到来直前では逆に心 拍数の減少が見られることがわかった。このよう に，反復して嫌悪事態を経験することによって， 不安反応の表出を抑制できるようになった。

このような現象が見られるのは, 表出される不 安は嫌悪刺激によって喚起された興奮がそのまま 表出されているのではなく，それを抑制する機構 を経て表出されている可能性を示唆するものであ る. Epstein (1967)は, 不安 (net anxiety：以後A と略) は興奮 (excitation：以後 $\mathrm{E}$ と略) と抑制 (inhibition：以後 I と略) の合成变量 $(\mathrm{A}=\mathrm{E}-$ I）として表出されるといらモデルを考えた (Fig. 1). EもI も時間や回数の一次関数として

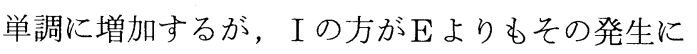
遅れがあり，しかも発生後の変化勾配が大きいと 仮定した。これにより，時間が経過し，つまり反 復回数が増えて，I>Eとなった場合に，不安を
抑制することができるようになると考えた。その 結果, 表出される不安の量は, Fig. 1 に示すよう にサイン曲線的な変化をすることになる．当然， 刺激状況や個人差によって $\mathrm{E}$ I $\mathrm{I}$ はさざまな值 をとりらると考学られることから, 表出される不 安もさまざまな值をとることが予想できる。

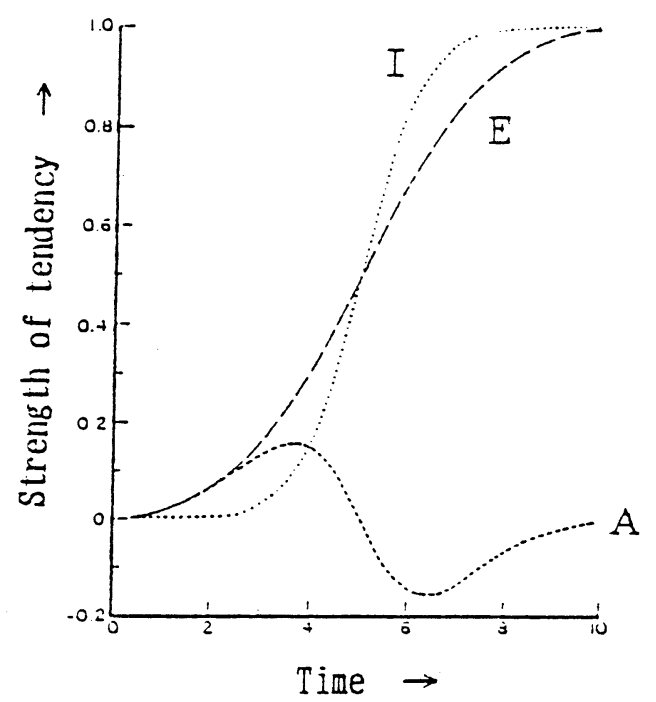

Fig. 1 Theoretical curves of excitation (E), inhibition (I), and net anxiety (A) as a function of time series cited by Epstein, S. (1967). The curve of net anxiety was obtained by subtracting inhibition from excitation.

Byrne (1964)は，個人の持つ嫌悪事態に対する 対処傾向には，感作 (sensitization) と抑圧 (repression) にまとめることができると述べてい る. 嫌悪事態に対して, 感作者 (sensitizer：以下 $\mathrm{S}$ と略）は事態に注意を向けるという接近的な対 処をとるのに対し，抑圧者（represser：以下 Rと 略）は注意をとらしたり，関係ないものに注意を 向けるといった回避的で抑圧的な対処をとる特徵 がある. Epsteinのモデルに当てはめて考えるな らば, Byrneの示した対処傾向の違いはI の違い に置き換えることができる，RはSよりも I の程 度が大きいと考えられる。同一刺激を $\mathrm{S}$ との被 験者に対して反復呈示し, 不安反応の様相を比較 することで, Epsteinのモデルに拈けるI の役割 を検証することが可能となる。 
本研究では，嫌悪刺激に対する対処傾向の異な る被験者を用いて，嫌悪刺激の反復暴露に伴ら不 安反応を調べ，Epsteinのモデルを検証すること を目的とした。

\section{方法}

＜被験者＞生和 (1972b)による日本版 R - S 尺 度を男子大学生 117 名に実施し，5 パーセンタイ ル得点に含まれる上位 6 名を $\mathrm{S}$ 群, 下位 6 名を $\mathrm{R}$ 群として用いた。年齢は18〜19歳であった。

<実験手続き> 被験者は実験室に入室後, 心拍 測定電極が装着された．実験室になれさせるため の数分間の慣化期間の後, 実験についての教示を 受けた。教示は以下の通りである。

「これから，電気ショックを受けてもらいま す。かなり痛いものですが，やけどしたり怪我を するほどではありませんから，安心して下さい． 目の前のディスプレイに，実験開始の合図が出た 後, 数字が表示されます。この数字はだんだん小 さくなっていき，「0」が表示されると同時に指 につけた電極から電気ショックを受けてもらいま す．その後も心拍を測定しますので，実験終了の 合図があるまで体を動かさないようにして下さ い.」

被験者は, 10回の試行を受けたが, 正確な回数 は知らせなかった。電撃を非利き手の第 2 ・第 3 指に $10 \mathrm{~mA}$ の強さで， 1 秒間与えた。電撃の到来 は, 数字のカウントダウンにより継時的に予告し た。 1 回の試行は, 電撃の到来を待つ予期期間 1 分とそれに続く回復時間 1 分からなり, 試行間間 隔は，約 5 分であった。

＜実験装置＞ 不安の生理指標である心拍数は， 日本電気三栄製ポリグラフ 360 システムを用いて 第 II 誘導法により測定し，レクチホリ $8 \mathrm{~K} て ゙$ 記録 した。電撃は, 日本光電製電気刺激装置 SEN3101 とアイソレーターSS-102Jを用いて与えた。 実験の制御及び心拍のサンプリングには，NEC 製パーソナルコンピュータ PC-9801VM2 を用い
た

＜測度と処理 $>$ 不安の測度には, 心拍数を用い た.心拍数は, 予期期間・回復期間を通して測定 したが，予期期間のみを検討の対象とした。予期 期間 1 分を 12 の間に分け, 区間内を算術平均し て心拍数の代表值を求めた. 反復に伴ら心拍数の 時系列変化パターンを検討するため, 10 回の反復 系列を前・中・後の 3 時期に分けて, 被験者群ご とに平均パターンを求めた. 前半は試行 1 から 3 まで, 中盤は試行 4 から 7 まで, 後半は試行 8 か ら10までをひとまとめとして集計した。その際， 全区間ともに区間 1 からの増分 $(\mathrm{bpm})$ を算出し, 相対的な变化パターンに修正した。

その後に, 主成分分析を行い, 時系列変化の共 通因子を抽出した。 固有值 1.0 以上の因子のみを 用い, 最小自乗推定法により因子得点を算出した (芝, 1979). R・S S 被験者群ごとに集計し, 反 復に伴ら時系列成分の推移を検討することにし た。な扔，主成分分析には12区間のデータをZ得 点化したものを用いた。

このように因子分析を用いたのは，複雑な時系 列変化をしている心拍数から共通する変化成分を 抽出するためである．各成分が反復に伴いどのよ らに変化していくかをみることで，より簡便に， 反復の効果を検討することができるものと思われ るからである。

\section{結果}

1. 反復に伴う心拍数の時系列変化パターン 10回の試行を前・中・後の 3 つの時期に分け, 被験者群ごとに心拍数の時系列変化パターンをプ ロットしたものが，Fig. 2 である。いずれも区間 1 からの相対変化量（bpm）で表してある，R・ $\mathrm{S}$ 群ともに, 時系列に伴う心拍数の変化量は, 試 行系列前半（試行 $1 \sim 3$ ）で大きく, 中盤（試行 $4 \sim 7$ ) や後半（試行 8～10）では少なくなって いる．Rと $\mathrm{S}$ とで大きく異なっているのは, 心拍 数の時系列変化パターンで, $\mathrm{R}$ は電撃到来直前で 
REPRESSER

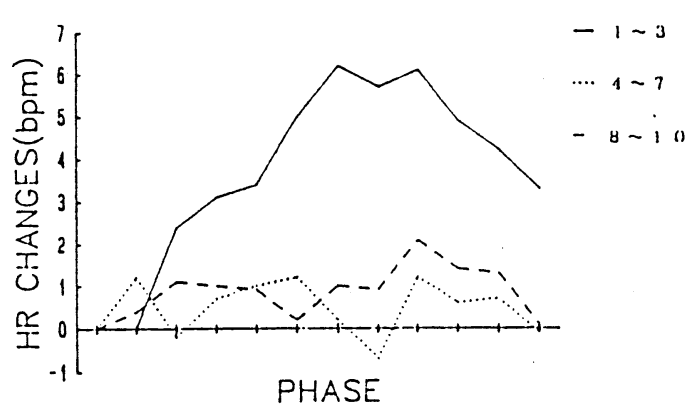

S E N S I T I Z E R

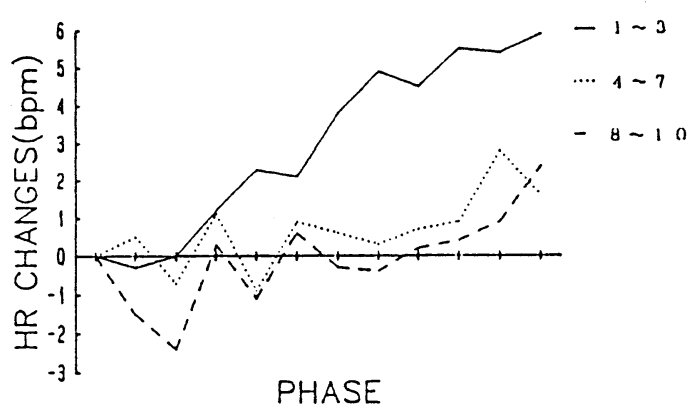

Fig. 2 Time series changes of HR for two experimental groups. Ten trials are divided into 3 periods, i. e., from trial 1 to 3 , from trial 4 to 7 , form trial 8 to 10 .

心拍数の減少を示すのに対し, Sでは増加する傾 向を示している. R群の方で電撃到来直前の不安 が抑压されやすいことがわかる。

\section{2. 因子分析による時系列変化パターンの抽出}

主成分分析法を用いて, 心拍数の時系列変化に 内在する共通因子の抽出を行った。固有值 1.0 以 上の因子は 3 因子抽出された。時系列を変量とし ていることから，因子構造をわかりやすくするた め, 図にプロットしたものが, Fig. 3である.ここ で得られた因子のプロフィールは，心拍数変化に 潜在しているパターンであるといらことができ る. 第 1 因子は, 予期期間が始まると因子負荷量 はやや増加し, その後一貫して減少し, 電撃到来 直前にやや増加するといらパターンを示してい る. 全体的にみれば予期期間を通して減少してい くパターンだといえる。第 2 内子は, 予期期間が

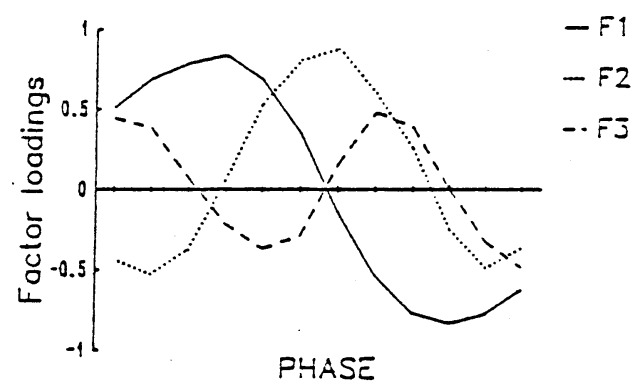

Fig. 3 Time series patterns of heart rate obtained by factor analysis. Factor 1 showed a pattern of monotonic decrease. Factor 2 showed a negative quadratic function. Factor 3 showed a negative cubic function.

始まると次第に因子負荷量が増加し，予期期間の 中間をピークに, その後減少していくパターンで ある、第 3 因子は，因子負荷量が減少・増加・減 少といら変化をしている.

このように，3つの因子の時系列変化をみる 之, 第 1 因子の直線性が若干低いものの, 第 1 因 子から順に, 1 次関数 - 2 次関数 - 3 次関数的な 時系列変化をしているといえる。こうした因子負 荷量の推移は, 時系列データを因子分析した時に 特徴的にみられるものであり，本報告においても 時系列データに潜在する共通因子が存在していた ことを示している。

\section{3. 因子得点による検討}

因子得点は，第 3 因子までの因子負荷量をもと に，最小自乗法により算出した。それを個人特性

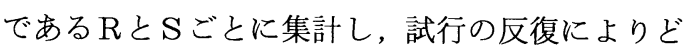
のように変化していくかを検討した。

Fig. 4 は，第 1 因子についてR・S 別に推移を 示したものである. 因子得点が負であれば, 電撃 到来に向けて単調に心拍数が増加するパターン を，正であれば逆に減少するパターンを示すこと を意味する。試行系列の前半では， Rより $\mathrm{S}$ の方 が負の因子得点を示し, 予期期間中心拍数が単調 に増加する傾向の強いことがわかる。しかし, 試 行系列が中盤になると因子得点もほとんど 0 を示 して和り, 単調増加傾向はみられなくなってい 


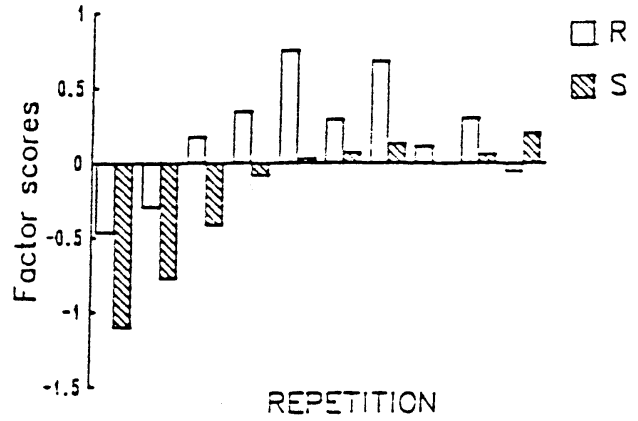

Fig. 4 Mean scores of factor 1 for sensitizer (S) and represser (R) groups, as a trial was repeated. Negative scores mean a positive simple function of heart rate. Positive scores mean negative.

る.一方, Rは, 試行系列前半はやや増加型の変 化傾向を示しているが，試行系列の中盤では因子 得点が正の值を示し, むしろ減少型の変化パター ンを示すことが多くなっている. 試行系列の後半 になると, S 同様，1 次関数的な变化を示すこと は少ない。

次に第 2 因子でみられた 2 次関数的な变化成分 の推移についてみてみると，Fig. 5 に示してある よらに， RとSでは大きな違い認められない。

$\mathrm{R} \cdot \mathrm{S}$ とも試行系列の前半から中盤にかけて因 子得点は正の值から負の值へと移行しており，2 次関数的な変化傾向が逆転している. R は S と比 ベて，第 1 試行から，負の第 1 因子的特徴を示さ ず，第 2 因子的特徵を示すことから，早い段階か ら電撃到来直前の心拍数増加を抑圧する傾向がみ

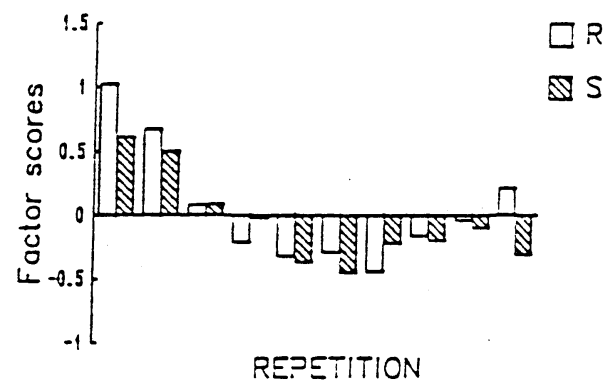

Fig. 5 Mean scores of factor 2 for sensitizer (S) and represser (R) groups, as a trial was repeated. Negative scores mean a positive quadratic function of heart rate. Positive scores mean negative.
られている。

第 3 因子的特徵の推移については, Fig. 6 に示 した通りである。 RとSの違いがみられるのは， 試行系列が後半になってからである，Rは正の第 3 因子的特徵を， S 快負の特徵を示している。つ まり, 電撃到来の直前で Rは心拍数が減少するの に対し, $\mathrm{S}$ は増加するといら, 全く逆の時系列変 化傾向を示している.

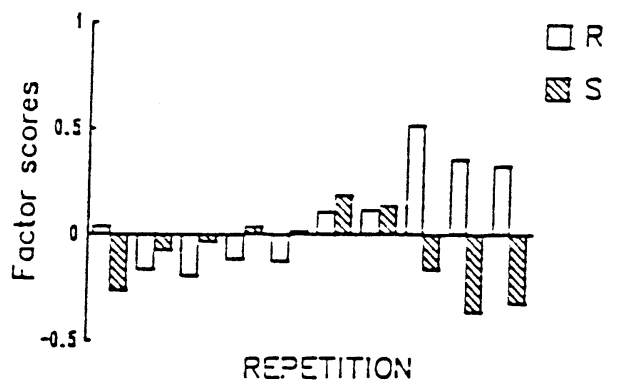

Fig. 6 Mean scores of factor 3 for sensitizer (S) and represser (R) groups, as a trial was repeated. Negative scores mean a positive cubic function of heart rate. Positive scores mean negative.

反復に伴う時系列変化の推移をまとめると, $\mathrm{R}$ で第 1 因子的特徵が試行系列中盤でみられる以外 は, 試行系列中盤以降, 第 1 - 第 2 因子的特徵が みられなくなっている。 それに対して, 試行系列 後半から第 3 因子的特徵がみられるよらになって きている、このような変化が生じたことは, 試行 を反復するにつれ，心拍数変化のトレンド的な長 周期成分が減少していき，比較的短い周期の変化 成分が優勢になってきたことを意味している。言 いかえれば，反復するにつれ変化成分の主座が入 れ替わったことを示している。

\section{考察}

心拍数変化の時系列変化パターンを主成分分析 した結果, 主要な因子として 3 因子が抽出でき た。 その因子構造を見ると, 第 1 因子から，1次 関数 - 2 次関数 $\cdot 3$ 次関数的とい5変化傾向を示 すことがわかった。これは時系列データを因子分 析した時に得られる特徴的なパターンであり,心 
拍数（生和, 1985）以外にも内田クレペリン作業 検查 (生和, 1972a) に捖いても共通してみられる 現象である．時系列データであることから，変量 が独立ではなく，乙かも時間的に接近している変 量の相関が高いといらシンプレックス構造をして いるために，このよらな形で因子が抽出されたの だと考えられる。

Epstein (1967) の不安表出モデルを検討するた め, 事態に対する対処傾向の違いを抑制傾向の違 いとして捉え, Byrne (1964)のR S スケールで被 験者を分けて, 反復に伴う不安反応の変化を調心 た。その結果, 試行を反復するにつれ, 被験者群 によって心拍数の変化パターンに違いが見られる ことがわかった。抑圧的な対処をするRは，刺激 到来直前での心拍数低下が見られ，事態に注意を 向任て対処する $\mathrm{S}$ は, 逆に増加する傾向を示し た。

予期期間中に継時的に嫌悪刺激の到来が予告さ れるといら最も予測可能性が高い実験条件であっ たことから，心拍数は嫌悪刺激の到来に向けて単 調に増加する上昇型の変化傾向を示しやすい (Monat et al., 1972). そのため, 始めはR・S ずれも上昇型の反応を示している。しかし, 反復 回数が増すにつれて, 次第に反応のピークが予期 期間の前半へと移行していく．Sではピークの移 行が予期期間中盤付近までしかみられていないの に対し， Rでは前半にまで移行するといら変化傾 向を示す。これは， $\mathrm{S} ょ り も \mathrm{R} て ゙ \mathrm{I}$ 傾向が強いこ とから, 比較的早い段階で I > E となってしまう ために生じたものと考えられる。このように，反 応のピークに移行がみられるといら本研究の結果 は, Epstein (1967)のモデルで裏付けられるもの といえる.さらに反復が増すと， R・S ともに 3 次関数的な反応パターンを示すようになり， Rで は負の, Sでは正の変化といらまったく逆の変化 傾向をしている。あくまでもS S 感作的な対処の 特徵である嫌悪刺激到来直前の反応増加がみら れ， $\mathrm{R}$ は抑圧的な対処の特徵である反応の低減が
みられている。

反復に伴って変化する心拍数の時系列変化パ ターンの推移を模式的にあらわしてみると， Sで は正の 1 次関数（単調増加）加負の 2 次関数 (逆U字), 正の 3 次関数へと推移していくのに 対し, Rでは正の 1 次関数（単調増加）から負の 1 次関数（単調減少）もしくは負の 2 次関数（逆 U字), 負の 3 次関数へと推移していくといえる. 反復の終盤に， S でみられた反応の正の 3 次関 数的変化は, Epsteinのモデルで示された合成変 量である net anxietyにきわめて類似した変化傾 向であることがわかる，それに対し， RはS $\mathrm{S}$ 逆 の傾向を示しており，EpsteinのモデルのIとE とを入れ替えて net anxietyを算出した時のよう な反応をしている。このように，Iの違いは反復 するにつれて大きくなり, 不安の表出に大きな影 響を与えている。

次に, 対処の違いに関係なくみられた傾向とし て, 変化の周期が挙げられる. 反復の前半では 1 次関数・ 2 次関数といった比較的トレンド的な変 化を示しているが, 後半になると 3 次関数のよら な周期の短い変化を示すようになることがわかっ た。ここでみられた 1 次関数的変化は，トレンド 的な長周期の変化であり，不安の成分と関係して いるといわれている（岩永・生和, 1986）。それに 対して, 比較的短周期の心拍変動は, むしろ嫌悪 事態に対する準備的な反応としての性質を持って いるといわれている. 反復に伴い, 長周期の変化 成分から短周期の変化成分へと移行していくこと は，以下のことを示しているものと考光られる。 つまり，嫌悪事態に慣れない段階では，不安が情 動の中心的な成分として表出されるが, 反復に伴 い，嫌悪事態に対する準備的な反応へ移行したの ではないかと考えられる。このことは, 単に反復 に伴って不安反応の時系列変化パターンに違いが 生じるだけではなく，内在する情動成分といら質 的な違いをも生じている可能性を示唆している.

今後は, 刺激強度等の刺激変数を操作すること 
によって，Eに関する検討をさらに行らと同時 に，予期期間にみられる不安反応の意味付けを明 確にしていく必要がある。

\section{引用文献}

Byrne, D. 1964 Repression-sensitization as a dimension of personality. In B. A. Maher (Ed.), Progress in Experimental Personality Research Vol. 1. New York : Academic Press.

Epstein, S. \& Fenz, W. D. 1965 Steepness of approach and avoidance gradients in humans as a function of experience : Theory and experiment. J. Exp. Psychol., 70, 1-12.

Epstein, S. 1967 Toward a unified theory of anxiety. In B. A. Maher (Ed.), Progress in Experimental Personality Research Vol. 4. New York : Academic Press.

Epstein, S. 1971 Heart rate, skin conductance, and intensity ratings during experimentally induced anxiety : Habituation within and among days. Psychophysiology, 8, 319-331.

岩永 誠・生和秀敏 1986 嫌覀状況下にみられ る指標間 synchrony 生理心理, 4, 11-17.

Monat, A., Averill, J. R., \& Lazarus, R. S. 1972

Anticipatory stress and coping reactions under various conditions of uncertainty. J. Pers. Soc. Psychol., 24, 237-253.

生和秀敏 1972a 内田クレペリン精神作業曲線 の因子分析的研究 - P.O 技法の適用による個 人内変異の検討一 心理学研究, 43, 176187.

生和秀敏 $1972 \mathrm{~b} \quad \mathrm{R}-\mathrm{S}$ 尺度の日本版作成のた めの試み(1) 広島大学教養部紀要 II， 6，79118.

生和秀敏 1985 不安喚起状況下に打㺭る心拍変 化の時系列解析 行動療法研究, 11, 1，2333.

芝 祐順 1979 因子分析法第 2 版 東京大学出 版会. 